\title{
Article
}

\section{The Effect of Comorbid Attention-Deficit/Hyperactivity Disorder Symptoms on Face Memory in Children with Autism Spectrum Disorder: Insights from Transdiagnostic Profiles}

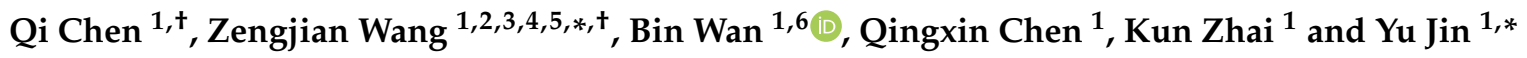 \\ 1 Department of Maternal and Child Health, School of Public Health, Sun Yat-Sen University, \\ Guangzhou 510080, China; chenq326@mail2.sysu.edu.cn (Q.C.); wanb.psych@outlook.com (B.W.); \\ chenqx36@mail2.sysu.edu.cn (Q.C.); zhaik@mail2.sysu.edu.cn (K.Z.) \\ 2 School of Psychology, South China Normal University, Guangzhou 510631, China \\ 3 Key Laboratory of Brain, Cognition and Education Sciences, South China Normal University, Ministry of \\ Education, Guangzhou 510631, China \\ 4 Center for Studies of Psychological Application, South China Normal University, Guangzhou 510631, China \\ 5 Guangdong Key Laboratory of Mental Health and Cognitive Science, South China Normal University, \\ Guangzhou 510631, China \\ 6 Max Planck Institute for Human Cognitive and Brain Sciences, 04103 Leipzig, Germany \\ * Correspondence: zengjianw@m.scnu.edu.cn (Z.W.); jinyu@mail.sysu.edu.cn (Y.J.) \\ + Qi Chen and Zengjian Wang should be considered joint first author.
}

\section{check for} updates

Citation: Chen, Q.; Wang, Z.; Wan, B.; Chen, Q.; Zhai, K.; Jin, Y. The Effect of Comorbid Attention-Deficit/Hyperactivity Disorder Symptoms on Face Memory in Children with Autism Spectrum Disorder: Insights from Transdiagnostic Profiles. Brain Sci. 2021, 11, 859. https://doi.org/ 10.3390/brainsci11070859

Academic Editor: Antonio Narzisi

Received: 18 May 2021

Accepted: 23 June 2021

Published: 28 June 2021

Publisher's Note: MDPI stays neutral with regard to jurisdictional claims in published maps and institutional affiliations.

Copyright: (C) 2021 by the authors Licensee MDPI, Basel, Switzerland. This article is an open access article distributed under the terms and conditions of the Creative Commons Attribution (CC BY) license (https:/ / creativecommons.org/licenses/by/ $4.0 /)$.
Abstract: Face memory impairments are common but heterogeneous in autism spectrum disorder (ASD), which may be influenced by co-occurrence with attention-deficit/hyperactivity disorder (ADHD). Here, we aimed to investigate the phenotype change of face memory in children with ASD comorbid ADHD symptoms, and discuss the potential role of executive function (EF). Ninety-eight children were analyzed in the present study, including ASD- (ASD-only, $n=24)$, ADHD ( $n=23)$, ASD+ (with ADHD symptoms, $n=23$ ) and neurotypical controls (NTC, $n=28$ ). All participants completed two tests: face encoding and retrieving task and Wisconsin Card Sorting Test (WCST) for measuring face memory and EF, respectively. Results revealed that: compared with the NTC group, children with ASD - exhibited lower accuracy in both face encoding and retrieving, and participants with ASD+ showed lower accuracy only in the retrieving, whereas no differences were found among participants with ADHD. Moreover, in the ASD+ group, face encoding performance was correlated with response perseverative errors (RPE) and failure to maintain sets (FMS) of WCST; significantly, there were no group differences between ASD+ and NTC in these two indices. The transdiagnostic profiles indicated that comorbid ADHD symptoms could modulate the face encoding deficiency of ASD, which may be partially compensated by EF. Shared and distinct intervention strategies to improve social cognition are recommended for children undergoing treatment for each condition.

Keywords: autism spectrum disorder; attention-deficit/hyperactivity disorder; face memory; executive function; comorbidity; heterogeneity; transdiagnostic

\section{Introduction}

Face memory impairment, being associated with social and cognition development, has been a candidate neurocognitive endophenotype of autism spectrum disorder (ASD) [1-4]. For example, better face memory performance of children with ASD could predict their lesser independent play and more cooperative interaction with peers [5]. Some scholars have even proposed that training on face memory is a promising method for improving social function in individuals with ASD [6]. Yet, the phenotypic manifestation of face memory in ASD remains insufficiently understood due to the striking heterogeneity [7-9].

ASD in children often co-occurs with symptoms of attention-deficit/hyperactivity disorder (ADHD), reaching approximately $1 / 2 \sim 2 / 3[10,11]$, that pose serious challenges 
to clinical practice and research data [12]. Recent perspectives have proposed that, for children with mild or high-functioning ASD, the ADHD-comorbid condition may mask their cognitive profiles, camouflage their difficulties, and led to their atypical phenotype changes [13-15]. Both ASD and ADHD face social difficulties, but their presentations are different: children with ASD primarily present in absence of positive behaviors, demonstrating limited social play and initiating fewer social interactions [16-18]; while ADHD predominantly manifest in the presence of negative behaviors including disobeying rules, inappropriate responses to others, and aggressive motions $[17,19,20]$. These shared and unique behavioral features between ASD and ADHD may originate from their diverse underpinning neurocognitive mechanisms [17], such as face memory deficits.

The deficiency of face memory has been widely reported in the ASD population $[2,21,22]$, however, there has been limited discussion of the detailed processing characteristics of them, and with mixed results. The successful use of memory depends on the manipulation of encoding, maintenance and retrieval [23]. Some findings suggest that the memory deficiency of ASD can be attributable to the anomalies in encoding, characterized by difficulties in abstracting stimuli' properties [24-26], whereas others hold that the attenuated face memory may be caused by atypical retrieval, reflected by the barriers in recalling existing information [5,27]. Neuroimaging studies have found that children with ASD presented underconnectivity between the fusiform face area (FFA) and the medial and rostral lateral prefrontal cortex during face memory encoding and retrieving [28]. For children with ADHD, it is still under debate whether they have face memory impairment or not. Previous studies have prompted that the face memory ability of individuals with ADHD would be less affected, with great likelihood of face retrieval being impacted [29-31]. For instance, Kim et al. [30] found that there were no group differences between ADHD and NTC in behavioral performance of memory retrieving, but participants with ADHD demonstrated lower neural processing efficiency. Such transdiagnostic cognitive phenotyping may be essential for understanding shared mechanisms underlying ASD and ADHD. Meanwhile, it will induce more uncertainties to the phenotype changes in children with ASD comorbid ADHD.

Studies have revealed that children having ASD with comorbid ADHD symptoms often present more severer social difficulties [32,33]. The strong relationship found between face memory and social behaviors suggests that children with comorbid conditions may have poorer abilities in face memory. However, notably, youth with comorbid conditions may display compounded characteristics of both disorders, having negative social behaviors as well as lacking positive ones [34]. As some scholars have proposed, this behavioral pattern that alternates between ASD and ADHD may result in unpredictable and atypical changes leading to impaired social cognition [17,35]. A study on event-related potentials (ERP) associated with emotional face memory found that children with ASD showed reduced N170 amplitude during memory encoding, and children with ADHD demonstrated reduced N400 amplitude during retrieving, while those with a comorbid condition performed abnormally during both encoding and retrieving [31]. These findings provided another possibility that ADHD-traits may alter the cognitive process of a child with ASD, to resemble the performance of an individual with ADHD.

To understand the underlying mechanisms of cognitive impairment in ASD and ADHD, executive function (EF) is one among the most robust tools [36-38]. It was found that EF plays an important role in social competence of ASD and ADHD [39,40], as well as being implicated in visual memory [41,42]. Zinke et al. [43] found that the visual memory performance of children with ASD was correlated with their ability of planning. Van et al. [44] found that executive dysfunction, rather than decreased storage capacity of information, contributed to explain visual memory impairments in ADHD. Although the exact relationship between face memory and EF has not been studied, both clinical practice and scientific investigation have prompted that $\mathrm{EF}$, like sustained attention and cognitive flexibility, may significantly function in processes involved in face memory. Moreover, transdiagnostic studies have shown that different components of EF could dissociate 
respective features of ASD and ADHD, especially in the neurocognitive phenotype [45-48]. In our former study, it was also found that diverse indices of EF measured by Wisconsin Card Sorting Test could explain visual memory performance of children with ASD and ADHD [49]. For children with a comorbid condition, their characteristics of EF were more affected by the ADHD-trait, irrespective formal diagnosis [35,50,51]. Therefore, it is significant to explore the potential role of EF on face memory in children with ASD and ADHD, and especially among children with comorbidity.

With a growing awareness of the complexity and significance of comorbidity in ADHD and ASD, an increasing number of studies have encouraged transdiagnostic approaches to explain their similarities and differences in etiology, associated impairments, and the interventions [13]. Thus, the present study had a three-folded purpose. First, to compare the transdiagnostic features of face memory between children with ASD and those with ADHD. Second, to further analyze the manifestation change in face memory among children with ASD comorbid ADHD symptoms. Third, to preliminary explore the correlation between face memory and EF.

\section{Materials and Methods}

The study procedure was approved by the medical ethics committee of the affiliated institute of the authors (consistent with the Declaration of Helsinki) prior to recruitment of participants. Written informed consent was obtained from the guardians. All participants did not take any central nervous system active medications in recent half years.

\subsection{Participants}

A convenience sample of 106 right-handed children, aged 6-12 years, was recruited through advertisement. The inclusion criteria were as follows: (1) having a full intellectual quotient (FIQ) score $\geq 70$, with normal naked vision or corrected-vision without color blindness; (2) having the ability to speak and comprehend Mandarin; (3) having no history or presence of neurological or severe medical illness, such as learning disorder, schizophrenia, bipolar disorder, major depressive disorder, anxiety disorder, etc.; and (4) completing all the administered measures. In addition, children with NTC were required to have normal (not clinical or subclinical) scores on both rating scales of ASD and ADHD symptoms.

Children with ASD or ADHD were previously diagnosed by professional pediatricians in licensed hospitals in Guangzhou City or Shenzhen City, and the diagnosis certificates were obtained from the guardians. Their diagnosis were then re-confirmed by two pediatricians and psychiatrists experienced in ASD and ADHD assessment, according to the DSM-5 [52]. Based on their scores on the Swanson, Nolan, and Pelham-IV rating scales (SNAP-IV), participants with ASD were divided into two groups: ASD - group (ASD-only, without ADHD symptoms) and ASD+ group (with ADHD symptoms). Moreover, two well-trained researchers have completed the behavioral observation and interview with guardians to confirm whether children with ASD had co-occurring with ADHD symptoms. Children with NTC were recruited from primary schools.

The Chinese version of the Wechsler Intelligence Scale for Children, fourth edition (C-WISC-IV), was used to assess the cognitive profile of all participants, which included full intellectual quotient (FIQ) and four sub-indices: verbal comprehension index (VCI), perceptual reasoning index (PRI), working memory index (WMI), and processing speed index (PSI).

\subsection{Clinical Characteristics}

The Child Autism Rating Scale (CARS) [53] and Social Responsive Scale (SRS-2) [54] were applied to assess ASD symptoms. The Chinese version of the 18-items SNAP-IV [55] was used to measure ADHD symptoms. The CARS was measured by two well-trained researchers in the present study. In addition, parents of all participants were instructed to rate their children's psychological and behavioral status according to their daily performance of the latest half years. 


\subsection{Face Memory}

The paradigm consisted of a face encoding task (FET) and a face retrieving task (FRT) to assess face memory performance (see Figure 1). Both tasks have been successfully applied in previous researches with different samples [56-58]. The participants were instructed to complete the FET first, which was followed by the FRT. The two sessions were divided by a short break of approximately $2 \mathrm{~min}$.

Face encoding task (FET): Each trial was preceded by a fixation (the character ' + ') presented at the center of the screen for $1000 \mathrm{~ms}$. Next, single pictures of neutral faces were presented for $4000 \mathrm{~ms}$ in a pseudo-randomized order, and participants were required to distinguish the gender of the facial images. They were instructed to press the ' $\mathrm{F}$ ' button if the person was female and press the ' $\mathrm{J}$ ' button if the person was male. Following this, the stimulus was replaced by a blank screen for another $1000 \mathrm{~ms}$ to complete the trial.

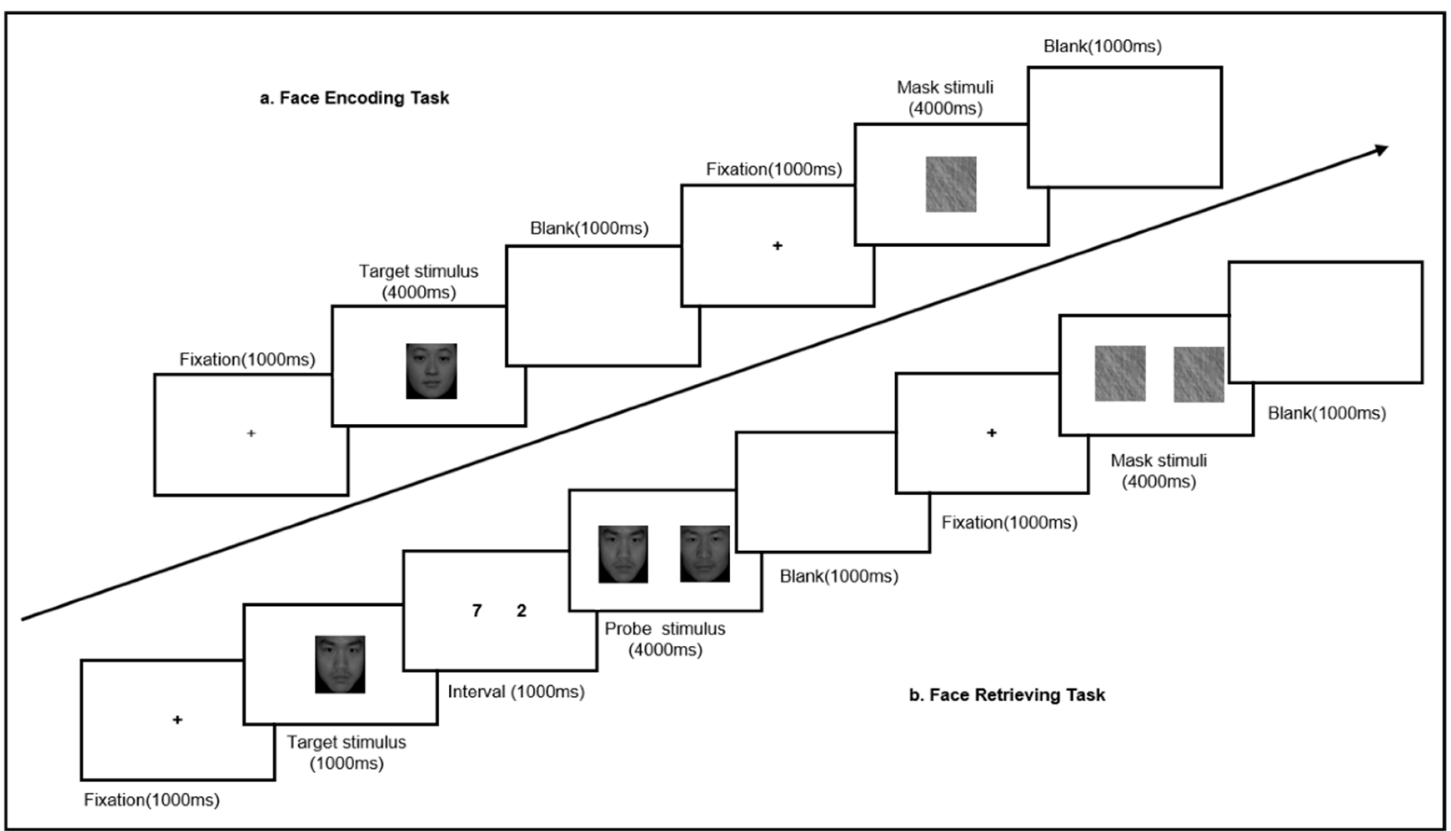

Figure 1. A demonstration of face encoding and retrieving paradigm. (a) Face encoding Task. (b) Face Retrieving Task.

Face retrieving task (FRT): Similar to FET, each trial of FRT began with a fixation for $1000 \mathrm{~ms}$. This was followed by a target stimulus which was presented at the center of the screen for $1000 \mathrm{~ms}$, and participants were asked to actively memorize each face. Next, two pictures—one previously presented and another new image—of faces were presented side by side for $4000 \mathrm{~ms}$. Participants were requested to select the previously presented face by pressing the ' $\mathrm{F}$ ' button if it appeared on the left, while pressing the ' $\mathrm{J}$ ' button if it appeared on the right. During the interval between the target and probe stimulus (1000 ms), the participants were asked to read out the two numbers appearing on the screen. Similar to FET, the trial ended with a blank screen for another $1000 \mathrm{~ms}$.

In addition, the mask blocks were used as the baseline condition. The stimulus were gray scrambled images which required participants to press the ' $\mathrm{J}$ ' button within $4000 \mathrm{~ms}$. Each task consisted of five blocks, including six trials of target stimulus and six mask stimuli, such that the FET was completed within $6 \mathrm{~min}$ and FRT was done within $7 \mathrm{~min}$. There were two practice blocks before the actual task, to enable the participants to learn the rules. The mean response time (RT) and accuracy (ACC) were recorded.

The face images were selected from the Chinese Facial Affective Picture System. The height of the picture was 300 pixels and the width was 260 pixels. The paradigm was designed using E-prime 2.0 and displayed on a 20-inch LCD screen $(1920 \times 1080$ pixels resolution). The visual stimuli were subtended at a visual angle of $0.5-1$ degree in the horizontal plane at eye-level. 


\subsection{Executive Function}

The Wisconsin Card Sorting Test (WCST) is a well-established measurement of EF [59]. Here, EF was examined by a computerized WCST which comprised of 128 reaction cards. The stimuli cards differed in colors, shapes, and numbers while the response card combined these factors to match the different stimuli cards based on diverse rules. This generated 11 familiar scores, and 4 indices were used in the present study: (1) categories completed (CC) reflecting the conceptual ability, (2) response errors (RE) reflecting the ability of switching, (3) response perseverative errors (RPE) revealing the ability of flexibility, and (4) failure to maintain sets (FMS) representing sustained attention.

\subsection{Statistical Analysis}

Data analysis was performed using the SPSS 25.0 software. First, multiple ShapiroWilk tests were conducted to inspect the distribution of quantitative variables, including age, score of CARS, score of SRS, score of SNAP-IV, score of WCST indices and the accuracy (ACC) and response time (RT) of face encoding and retrieving. Based on the results, parametric tests were employed for normally distributed variables and non-parametric tests were used for non-normally distributed variables (including PSI, CARS score, SRS subdomain scores, and indices of WCST).

Second, a one-way analysis of variance (ANOVA) or Kruskal-Wallis test was performed to determine the group differences in demographic characteristics, related symptoms, and face memory performance, and a Bonferroni correction was used for multiple comparisons. In addition, analysis of covariance (ANCOVA) was applied to compare face memory performance among the four groups after controlling for age and PSI/FIQ.

Third, a Pearson/Spearman correlation analysis was carried out to test the relationship between face encoding and retrieving ability and the symptoms of ASD and ADHD. Furthermore, multi-level linear regression analysis was employed to explore the relationship between EF and face memory performance. The size of test was set at $\alpha=0.05$.

\section{Results}

\subsection{Sample Characteristics}

Six participants including children with ASD- $(\mathrm{n}=2)$, ADHD $(\mathrm{n}=1)$, and ASD+ $(n=3)$ were excluded as they could not accomplish the behavioral tasks. Furthermore, an initial screening based on the omission rate of the mask-task was conducted to yield two outlier participants ( $Z$ score beyond \pm 3 of the sample as a whole). Thus, a total of 98 participants (24 ASD-, 23 ADHD, 23 ASD+, 28 NTC) were included in the final analysis.

The sociodemographic and clinical information of the participants are shown in Table 1. There were no significant group differences in age $\left(F_{(3.94)}=2.602, p=0.745\right)$ or sex distribution $\left(\chi^{2}=2.048, p=0.562\right)$. Instead, group differences were observed in the FIQ $\left(F_{(3.94)}=5.395, p=0.002, \eta^{2}=0.147\right)$ and PSI $\left(H_{(3.94)}=21.954, p<0.001\right)$ scores. Furthermore, the post hoc test showed that the ASD+ group presented lower FIQ scores compared to the NTC group $(t=-16.627, p=0.001)$, and all clinical groups had lower PSI scores than NTC (all pairwise comparisons, $p \leq 0.005$ ).

There were significant differences in the total score of CARS $\left(H_{(3.94)}=80.265, p<0.001\right)$, $\operatorname{SRS}\left(F_{(3.94)}=30.821, p<0.001, \eta^{2}=0.496\right)$, and SNAP-IV $\left(F_{(3.94)}=35.030, p<0.001, \eta^{2}=0.531\right)$ among the groups. In the scores on CARS, children with ASD - and ASD+ scored higher than those with ADHD and NTC (all pairwise comparisons, $p \leq 0.001$ ), and children with ADHD scored higher than NTC $(z=21.659, p=0.04)$. In SRS, the ASD+ group scored higher than the other three groups (all pairwise comparisons, $p \leq 0.001$ ), and both ASD - and ADHD groups scored higher than NTC (ASD - vs. NTC, $t=23.804, p<0.001$; ADHD vs. NTC, $t=16.950, p=0.013)$. In SNAP-IV, the post hoc test demonstrated that the ADHD and ASD+ groups scored higher than the ASD - and NTC groups (all pairwise comparisons, $p$ $\leq 0.001$ ). This reflected that the sample of the four groups was well-characterized in the clinical profile. 
Table 1. Demographic characteristics of the participants $(n=98)$.

\begin{tabular}{|c|c|c|c|c|c|c|c|}
\hline & ASD- & ADHD & ASD+ & NTC & $F / H$ & $p$ & Post hoc \\
\hline Male (\%) & $21(87.5 \%)$ & $21(91.3 \%)$ & $20(87 \%)$ & $22(78.6 \%)$ & 1.708 & 0.662 & \\
\hline Age & $7.8 \pm 1.8$ & $8.3 \pm 1.4$ & $7.9 \pm 1.8$ & $8.2 \pm 1.8$ & 0.412 & 0.745 & \\
\hline FIQ & $97.8 \pm 17.7$ & $98.6 \pm 15.8$ & $92.1 \pm 17.4$ & $108.7 \pm 9.5$ & 5.395 & 0.002 & $3<4$ \\
\hline $\mathrm{VCI}$ & $97.2 \pm 16.4$ & $103.7 \pm 13.5$ & $93.1 \pm 18.3$ & $111.3 \pm 10.5$ & 7.429 & $<0.001$ & $1,3<4$ \\
\hline PRI & $104.1 \pm 18.2$ & $104.0 \pm 17.6$ & $98.4 \pm 17.5$ & $110.2 \pm 10.9$ & 2.276 & 0.085 & - \\
\hline WMI & $100.8 \pm 18.7$ & $95.4 \pm 14.2$ & $94.8 \pm 15.2$ & $101.8 \pm 13.9$ & 5.536 & 0.136 & - \\
\hline PSI & $87.5 \pm 13.6^{\wedge}$ & $88.6 \pm 14.1$ & $86.8 \pm 19.2^{\wedge}$ & $100.7 \pm 9.8$ & 21.954 & $<0.001$ & $1,2,3<4$ \\
\hline $\begin{array}{l}\text { CARS \# } \\
\text { SRS }\end{array}$ & $31.4 \pm 2.2$ & $20.0 \pm 1.8$ & $31.4 \pm 2.6$ & $16.7 \pm 1.5$ & 80.265 & $<0.001$ & $1,3>2>4$ \\
\hline Total score & $69.4 \pm 22.1$ & $62.5 \pm 18.2$ & $96.8 \pm 18.7$ & $45.6 \pm 17.4$ & 30.821 & $<0.001$ & $3>1,2>4$ \\
\hline Awareness & $9.5 \pm 2.9$ & $9.8 \pm 2.5$ & $12.4 \pm 2.2$ & $8.0 \pm 1.9$ & 14.148 & $<0.001$ & $3>1,2,4$ \\
\hline Cognition & $13.1 \pm 4.8$ & $12.8 \pm 4.2$ & $19.6 \pm 4.1$ & $8.8 \pm 4.2$ & 26.515 & $<0.001$ & $3>1,2>4$ \\
\hline Communication & $23.9 \pm 8.7$ & $19.8 \pm 6.9$ & $31.5 \pm 7.7$ & $13.4 \pm 7.3^{\wedge}$ & 24.698 & $<0.001$ & $3>1,2>4$ \\
\hline Motivation & $10.4 \pm 3.4$ & $9.9 \pm 3.4^{\wedge}$ & $13.5 \pm 4.5^{\wedge}$ & $9.4 \pm 4.3^{\wedge}$ & 5.171 & 0.002 & $3>2,4$ \\
\hline $\begin{array}{c}\text { Autistic behavior } \\
\text { SNAP }\end{array}$ & $12.4 \pm 6.3$ & $10.1 \pm 5.9$ & $19.8 \pm 5.5$ & $6.0 \pm 3.2$ & 30.107 & $<0.001$ & $3>1,2>4$ \\
\hline Total score & $36.3 \pm 5.1$ & $46.7 \pm 6.6$ & $47.8 \pm 6.6$ & $33.0 \pm 6.6$ & 35.030 & $<0.001$ & $2,3>1,4$ \\
\hline Inattention & $20.5 \pm 2.7$ & $26.0 \pm 4.3$ & $26.1 \pm 2.1$ & $18.7 \pm 3.9$ & 31.226 & $<0.001$ & $2,3>1,4$ \\
\hline Hyperactivity & $15.2 \pm 3.7$ & $20.7 \pm 4.5$ & $21.7 \pm 5.9$ & $14.3 \pm 3.6$ & 16.232 & $<0.001$ & $2,3>1,4$ \\
\hline
\end{tabular}

Note: \# variance inequality; ^ distributed non-normally; ASD-, autism spectrum disorder (without ADHD symptoms); ADHD, attentiondeficit/hyperactivity disorder; ASD+, ASD children with ADHD symptoms; NTC, neurotypical controls; FIQ, full intellectual quotient; VCI, verbal comprehensive index; PRI, perceptual reasoning index; WMI, working memory index; PSI, processing speed index; 1 , ASDgroup; 2, ADHD group; 3, ASD+ group; 4, NTC group.

\subsection{Ability of Face Memory}

At first, the ANOVA results showed group differences of RT in the mask condition in both FET and FRT, which implied that the basic response level may be unequal for the four groups. To address this, an analysis of covariance (ANCOVA) was further conducted after controlling for age and PSI, and age and FIQ, respectively. Considering our former study which indicated that face memory performance would be affected by processing speed index of WISC-IV [60], and that the two results controlling PSI or FIQ were similar, in this context, the results of ANCOVA after controlling age and PSI are primarily reported. (see detailed in Table 2).

The ANCOVA results revealed that there were no significant interactions between group and age $\left(F_{(3.94)}=1.131, p=0.341\right)$, nor between group and PSI $\left(F_{(3.94)}=1.215, p=0.309\right)$. Notably, there were significant group differences in ACC of encoding $\left(F_{(3.94)}=5.145, p=0.002\right.$, $\left.\eta^{2}=0.144\right)$ and ACC of retrieving $\left(F_{(3.94)}=9.641, p<0.001, \eta^{2}=0.239\right)$. Multiple comparisons (using Bonferroni correction) indicated that children with ASD - exhibited a lower ACC than children with ADHD $(t=-0.128, p=0.026)$ and NTC $(t=-0.159, p=0.003)$ in FET; and in FRT, both children with ASD- and those with ASD+ displayed a lower ACC than those with ADHD and NTC (ASD - vs. ADHD, $t=-0.197, p<0.001$; ASD - vs. NTC, $t=-0.172, p=0.001$; ASD+ vs. ADHD, $t=-0.158, p=0.003$; ASD + vs. NTC,$t=-0.133$, $p=0.023)$. 
Table 2. Group differences in face encoding and retrieving performance.

\begin{tabular}{|c|c|c|c|c|c|c|c|c|c|c|c|}
\hline & ASD- & ADHD & ASD+ & NTC & $F_{1}$ & $P_{1}$ & $F_{2}$ & $P_{2}$ & $F_{3}$ & $P_{3}$ & Post hoc \\
\hline FET & & & & & & & & & & & \\
\hline ACC & $0.61 \pm 0.16$ & $0.74 \pm 0.20$ & $0.67 \pm 0.14$ & $0.81 \pm 0.10$ & 7.928 & $<0.001$ & 5.145 & 0.002 & 5.323 & 0.002 & $1<2,4$ \\
\hline RT & $\begin{array}{c}1547.13 \pm \\
359.04\end{array}$ & $\begin{array}{c}1377.73 \pm \\
239.38\end{array}$ & $\begin{array}{c}1532.99 \pm \\
437.97\end{array}$ & $\begin{array}{c}1274.72 \pm \\
283.12\end{array}$ & 3.868 & 0.012 & 2.024 & 0.116 & 2.775 & 0.046 & - \\
\hline RT-mask & $\begin{array}{c}813.82 \pm \\
207.01\end{array}$ & $\begin{array}{c}678.47 \pm \\
129.67\end{array}$ & $\begin{array}{c}862.73 \pm \\
245.45\end{array}$ & $\begin{array}{c}648.71 \pm \\
243.09\end{array}$ & 5.442 & 0.002 & 2.998 & 0.035 & 3.362 & 0.022 & - \\
\hline $\begin{array}{l}\text { FRT } \\
\text { ACC }\end{array}$ & $0.60 \pm 0.17$ & $0.81 \pm 0.14$ & $0.64 \pm 0.16$ & $0.81 \pm 0.17$ & 12.118 & $<0.001$ & 9.641 & $<0.001$ & 9.131 & $<0.001$ & $1,3<2,4$ \\
\hline RT & $\begin{array}{c}1283.16 \pm \\
457.58\end{array}$ & $\begin{array}{c}1263.17 \pm \\
312.42\end{array}$ & $\begin{array}{c}1175.17 \pm \\
421.23\end{array}$ & $\begin{array}{c}1058.83 \pm \\
280.75\end{array}$ & 1.973 & 0.123 & 1.780 & 0.156 & 1.920 & 0.059 & - \\
\hline RT-mask & $\begin{array}{c}580.81 \pm \\
173.31\end{array}$ & $\begin{array}{c}539.03 \pm \\
159.50\end{array}$ & $\begin{array}{c}554.92 \pm \\
143.52\end{array}$ & $\begin{array}{c}485.75 \pm \\
135.74\end{array}$ & 1.808 & 0.151 & 0.659 & 0.580 & 0.785 & 0.505 & - \\
\hline
\end{tabular}

Note: $F_{1}, P_{1}$ : the results of ANOVA; $F_{2}, P_{2}$, and post hoc: the results of ANCOVA controlling for age and PSI; $F_{3}, P_{3}$ : the results of ANCOVA controlling for age and FIQ; FET, face encoding task; FRT, face retrieving task; 1, ASD - group; 2, ADHD group; 3, ASD+ group; 4, NTC group; ACC, accuracy; RT, response time.

\subsection{Correlation between Face Encoding and Retrieving and the Symptoms of ASD and ADHD}

Table 3 shows the results of the Pearson correlation analysis (or Spearman analysis) between behavioral performance and the SRS and SNAP scores. In the ASD- group, RT-encoding was associated with SRS total score $(r=-0.411, p=0.046)$, social awareness $(r=-0.462, p=0.023)$, social cognition $(r=-0.455, p=0.025)$ and autistic behaviors $(r=-0.418, p=0.042)$, while ACC-retrieving $(r=-0.418, p=0.042)$ and RT-retrieving $(r=-0.406, p=0.049)$ were associated with social cognition. In contrast, in the ADHD group, only ACC-retrieving was found to be negatively correlated with social motivation $(r=-0.428, p=0.041)$. As for children with ASD+, ACC-encoding was associated with SRS scores, including total score $(r=-0.433, p=0.039)$, and social motivation $(r=-0.521$, $p=0.011)$, and RT-retrieving was associated with social awareness $(r=-0.593, p=0.003)$. Moreover, it was found that RT-encoding was correlated with SNAP total score $(r=-0.497$, $p=0.016)$ and the sub-index of hyperactivity $(r=-0.550, p=0.007)$. Additionally, a multiple linear regression controlling age and FIQ was conducted, and the results are demonstrated in Supplementary Table S1.

Table 3. Correlation between face memory performance and symptoms of ASD and ADHD.

\begin{tabular}{|c|c|c|c|c|c|c|c|c|c|c|c|c|}
\hline & \multicolumn{4}{|c|}{$A S D-(n=24)$} & \multicolumn{4}{|c|}{$\operatorname{ADHD}(n=23)$} & \multicolumn{4}{|c|}{ ASD+ $(n=23)$} \\
\hline & \multicolumn{2}{|c|}{ Encoding } & \multicolumn{2}{|c|}{ Retrieving } & \multicolumn{2}{|c|}{ Encoding } & \multicolumn{2}{|c|}{ Retrieving } & \multicolumn{2}{|c|}{ Encoding } & \multicolumn{2}{|c|}{ Retrieving } \\
\hline & ACC & RT & ACC & RT & $\mathrm{ACC}$ & RT & ACC & RT & ACC & RT & ACC & RT \\
\hline SRS & & & & & & & & & & & & \\
\hline Total score & -0.271 & $-0.411 *$ & -0.219 & -0.366 & -0.124 & 0.012 & -0.278 & 0.231 & -0.433 * & -0.108 & -0.403 & -0.313 \\
\hline Awareness & -0.154 & $-0.462 *$ & 0.045 & -0.245 & 0.036 & -0.273 & -0.135 & 0.196 & -0.129 & -0.314 & 0.151 & $-0.593^{* *}$ \\
\hline Cognition & -0.339 & $-0.455 *$ & $\begin{array}{c}-0.418 \\
*\end{array}$ & $-0.406^{*}$ & -0.118 & -0.032 & -0.061 & 0.101 & -0.372 & 0.000 & -0.317 & -0.243 \\
\hline Communication & -0.194 & -0.294 & -0.227 & -0.324 & -0.072 & 0.000 & -0.263 & 0.174 & -0.286 & -0.183 & -0.395 & -0.210 \\
\hline Motivation & -0.202 & -0.107 & -0.033 & -0.199 & 0.100 & 0.132 & $-0.428^{*}$ & 0.412 & $-0.521 *$ & 0.210 & -0.382 & -0.230 \\
\hline $\begin{array}{c}\text { Autistic behavior } \\
\text { SNAP }\end{array}$ & -0.244 & $-0.418^{*}$ & -0.138 & -0.307 & 0.290 & 0.097 & -0.200 & 0.113 & -0.337 & -0.157 & -0.331 & -0.164 \\
\hline Total score & -0.266 & -0.199 & -0.254 & -0.260 & -0.345 & 0.129 & -0.077 & 0.423 & 0.167 & $-0.497^{*}$ & 0.160 & -0.389 \\
\hline Inattention & -0.089 & -0.131 & -0.317 & -0.295 & -0.280 & 0.016 & 0.014 & 0.298 & 0.317 & -0.002 & -0.011 & -0.197 \\
\hline Hyperactivity & -0.307 & -0.183 & -0.122 & -0.147 & -0.239 & 0.174 & -0.127 & 0.337 & 0.071 & $-0.550 * *$ & 0.181 & -0.360 \\
\hline
\end{tabular}

Note: ${ }^{*} p<0.05 ;{ }^{* *} p<0.01$; ASD-, autism spectrum disorder (without ADHD symptoms); ADHD, attention-deficit/hyperactivity disorder; ASD+, ASD children with ADHD symptoms; ACC, accuracy; RT, response time; SRS, social response scale; SNAP, Swanson, Nolan, and Pelham-IV rating scales.

\subsection{Association between Face Memory and Executive Function}

In the comparison of EF, all clinical groups had lower score in CC compared to the NTC group $\left(H_{(3.94)}=18.781, p<0.001\right.$; all pairwise comparison, $\left.p<0.05\right)$; and participants with ADHD and those with ASD+ scored higher than NTC in the index of RE $\left(H_{(3.94)}=16.886\right.$, $p=0.001$; ADHD vs. NTC, $p=0.001$; ASD+ vs. NTC, $p=0.006)$. There were no group differences in RPE and FMS (see Table 4). 
Table 4. Group differences of WCST indices.

\begin{tabular}{cccccccc}
\hline & ASD - & ADHD & ASD+ & NTC & H & $p$ & Post hoc \\
\hline CC & $4(2.6)$ & $2(2.6)$ & $2(2.6)$ & $5(2.6)$ & 18.781 & $<0.001$ & $1,2,3<4$ \\
RE & $57(16.82)$ & $75.5(16.107)$ & $78(27.95)$ & $42(9.107)$ & 16.886 & 0.001 & $2,3<4$ \\
RPE & $6(1.11)$ & $6(2.12)$ & $4(1.37)$ & $7(2.30)$ & 1.753 & 0.188 & - \\
FMS & $2(0.4)$ & $1(0.4)$ & $1(0.3)$ & $1(0.5)$ & 2.158 & 0.540 & - \\
\hline
\end{tabular}

Note: CC, categories completed; RE, response errors; RPE, response perseverative errors; FMS, failure to maintain sets; 1, ASD- group; 2 , ADHD group; 3, ASD+ group; 4, NTC group.

To explore the relationship between EF and performance of face encoding and retrieving performance, a multi-linear regression analysis (stepwise) adjusting for age and FIQ was employed. The results (see Table 5) illustrated that CC predicted $25.8 \%$ individual variation of ACC-retrieving in ASD- group $\left(F_{(1.22)}=7.660, p=0.011, R^{2}=0.258\right)$, and RPE predicted $26.8 \%$ individual difference of RT-retrieving in the $\operatorname{ADHD}$ group $\left(F_{(1.21)}=7.672\right.$, $\left.p=0.011, R^{2}=0.268\right)$. In the ASD+ group, RPE and FMS predicted $33.8 \%$ performance of RT-encoding $\left(F_{(1.20)}=5.104, p=0.016, R^{2}=0.338\right)$, and RPE predicted $35.3 \%$ performance of RT-retrieving $\left(F_{(1.21)}=11.438, p=0.003, R^{2}=0.353\right)$. None of the of the EF indices predicted the performance of face encoding and retrieving in the NTC group. A Spearman correlation analysis between face memory and EF was also conducted, and the results are demonstrated in Supplementary Table S2.

Table 5. Multiple regression analysis between EF and VSWM across groups.

\begin{tabular}{cccccccc}
\hline Group & Dependent & Independent & $\boldsymbol{\beta}$ (SE) & $\boldsymbol{b}^{\prime}$ & $\boldsymbol{t}$ & $\boldsymbol{p}$ & $\boldsymbol{R}^{\mathbf{2}}$ \\
\hline ASD- & ACC-Retrieving & CC & $0.043(0.016)$ & 0.508 & 2.768 & 0.011 & 0.285 \\
ADHD & RT-Retrieving & RPE & $-40.781(14.724)$ & -0.517 & -2.770 & 0.011 & 0.268 \\
ASD+ & RT-Encoding & FMS & $163.741(72.155)$ & 0.414 & 2.269 & 0.034 & 0.338 \\
& & RPE & $15.541(7.435)$ & 0.381 & 2.090 & 0.050 & \\
& RT-Retrieving & RPE & $23.284(6.855)$ & 0.594 & 3.382 & 0.003 & 0.353 \\
\hline
\end{tabular}

Note: ASD-, autism spectrum disorder (without ADHD symptoms); ADHD, attention-deficit/hyperactivity disorder; ASD+, ASD children with ADHD symptoms; CC, categories completed; RE, errors responses; RPE, perseverative responses errors; FMS, failure to maintain set; ACC, accuracy; RT, response time.

\section{Discussion}

On the basis of disclosing the transdiagnostic commonalities and differences between ASD and ADHD, this study has elucidated an interesting issue about the phenotype change of face memory in children with ASD comorbid ADHD symptoms. The findings revealed that, (1) children with ASD - exhibited lower accuracy than NTC in both face encoding and retrieving, and participants with ADHD behaved similar to NTC, while those with ASD+ performed poorer than NTC only in face retrieving; (2) the face memory performance of all clinical groups were correlated with social behaviors reflected by SRS scores, but children with ASD+ continued to show an association between face encoding and ADHD symptoms measured by SNAP scores; (3) diverse indices of EF assessed by WCST could partially explain the manifestation of face memory in children with ASD-, ADHD and ASD+, respectively.

\subsection{Transdiagnostic Features of Face Memory in Children with ASD and ADHD}

As we hypothesized, the current study replicated the well-documented findings that children with ASD have general face memory deficits [22,61,62], and further affirmed that deficits are present both in the encoding and retrieval phases. In the behavioral aspect, Gaigg et al. [25] found that children with ASD present a lower accuracy than NTC in a three-order load paradigm of memory encoding, while Cooper et al. [27] found that they made more errors in a continuous memory recalling task. In the aspect of neural mechanism, functional magnetic resonance imaging (fMRI) studies indicated that children with ASD have lower neural processing efficiency during face encoding and retrieving, 
respectively [28,63]. Furthermore, results of this study found that face memory performance of children with ASD correlated with their social behaviors, as most previous studies demonstrated $[2,3,5]$. Remarkably, the insight from twin studies indicated that the heritable influences on face memory competence were associated with the social deficit aspect of autistic trait $[2,3,64]$. Since visual encoding competence sets the stage for successful face memory, strategic learning of early face encoding may enhance face recognition in children with ASD, and could show promise to remediate their social skills.

Consistent with previous studies [21,49,65], our findings did not support the prevalence of face memory deficits in children with ADHD. In addition, face memory performance of participants with ADHD were also found to be correlated with social behaviors, while the severity of social dysfunction in ADHD was milder than those with ASD (reflected by lower scores on CARS and SRS). Therefore, individuals with ADHD may possess more knowledge of social skills, which is supported by better social cognition, such as with face memory [17]. Notably, being affected by the ADHD trait impacts the manifestation of social dysfunction in children with ADHD in a manner different from those with ASD. For example, children with ADHD are unable to concentrate their attention on the memory information and are distracted by their surroundings and other social cues, which increases their social difficulties $[17,66]$. Thus, the effect of ADHD-traits should not be neglected when discussing the relationship between face memory and social function in the ADHD population.

The above findings indicated that the features of face memory could differentiate ASD and ADHD to be the transdiagnostic cognitive phenotype. Several causes could be responsible for their diverse behavioral presentation, and the distinct anomalous social visual attention pattern is a relevant issue yet to be explored in depth [67]. Patients with ASD have shown local processing preference on encoding visual information, and had difficulty in adopting chunking strategies to integrate the visual details [68-70]. Meanwhile, meta-analysis indicated that using a visual reminder, as a form of compensatory processing, may help to improve memory encoding and further enhance visual memory competence [71]. The autistic-like processing style seemingly suggested that face memory has already been impaired in the early encoding stage. On the contrary, individuals with ADHD failed to abstract targeted visual information when facing multiple stimuli or stimuli with complex details $[66,72]$. Accordingly, it was inferred that this ADHD-like processing style would be characterized by relatively intact ability in memory encoding but with some difficulties in retrieval.

\subsection{Characteristic of Face Memory in Children with ASD Comorbid ADHD Symptoms}

While there were prone to more severe social dysfunction, participants with ASD comorbid ADHD did not demonstrate poorer performance in face memory. The behavioral data suggested that children with the comorbid condition may present an additive effect: they performed as well as NTC in the face encoding task (like participants with ADHD), and made more errors in the face retrieving (similar to participants with ASD). This indicated that co-occurrence with ADHD symptoms would make the cognitive profile of ASD unpredictable, rather than having a simple effect of aggravation or alleviation of preexisting deficits. Regarding face memory phenotype change in children with ASD comorbid ADHD symptoms, some speculations could be made, which are presented below.

First, being affected by the ADHD trait, children with ASD comorbid ADHD symptoms may adopt an ADHD-like processing pattern during face encoding. Correlation analysis showed that the face encoding competence of the ASD+ group was associated with ADHD symptoms except for the established relationship between face memory and social function. As previous studies have emphasized the predominant role of attention condition, such as with attention allocation and distractibility in memory processing of both ASD and ADHD [21,73,74], an ADHD-like cognitive style would change the local processing preference of children with ASD. More significantly, the "additive model" has 
hypothesized that individuals with the comorbid condition are likely to manifest the separate characteristic of ASD and ADHD, to exhibit a confluence of the two [75].

Second, the phenomenon of mismatch between social dysfunction and face memory deficiency in children with the comorbid condition could be associated with the cognitive compensation mechanism. Recently, some scholars have pointed out that some patients with ASD may "compensate" for their underlying difficulties: in order to navigate the challenges associated with their core symptoms, they may mobilize more other cognitive resources such as EF and IQ [76-78]. Livingston et al. [77] conducted the first experimental study to confirm that some children with ASD could compensate their deficiency of social cognition by relatively improved utilization of EF. Furthermore, neuroimaging studies have found that children with ASD demonstrated increased hippocampal recruitment in memory encoding, and exhibited more activation within multiple prefrontal cortex areas when viewing faces, which were believed to be mechanisms of compensatory neural processing $[79,80]$. Although these findings are not sufficient to establish any conclusion, the studies provide interesting and significant opinions that require further exploration.

\subsection{Relationship between EF and Face Memory}

Importantly, recent perspectives have proposed that the special relationship between EF and social cognition deficits could explain the co-occurrence of ADHD symptoms in ASD [81]. Moreover, EF may impact social competence by facilitating higher-order cognition such as visual memory processing [39]. As part of a preliminary exploration, the present study found that different indices of WCST representing EF could explain the face retrieval performance in ASD-, ADHD, and ASD+ group, respectively. Consistently, previous studies have illustrated the close relationship between EF and visual memory in both ASD and ADHD populations [41,43,44,82]. Our former study had also demonstrated that varying components of EF could be dissociated with visual memory in ASD and ADHD [49]. Thus, the distinct features of EF may contribute to different visual processing patterns in children with ASD and ADHD, and result in their differing behavioral performance of face memory.

Of further interest, some scholars suggested that the ability of EF may have an important compensation function in patients with ASD [77,78]. In the present study, children with ASD comorbid ADHD symptoms also showed a correlation between face encoding and EF, including FMS and RPE in the WCST. While children with the comorbid condition scored as well as participants with NTC in these two indices. It is posited that children with the comorbid condition may mobilize their limited but relatively intact EF components to compensate for their face encoding deficits. In a pilot cognitive intervention research, Macoun et al. [83] found that visual memory competence of children with ASD would be remediated substantially through the compensatory training of EF. This shows promise in the development of intervention methods for improving social cognition. However, participants with ASD and ADHD present different features on EF [45,46,50], and children with a comorbidity were more affected by the ADHD trait [35,50]. Thus, shared and distinct interventional approaches would be necessary for each condition.

\subsection{Limitations and Future Directions}

The present study has some limitations. First, the age span across our participants (6.02 12.64 years old) was considered too wide, and the intelligence level of ASD+ and NTC groups were mismatched. Thus, age and PSI/FIQ were included as covariance. Further studies are warranted to test the effects of age. Second, although the data dissociated the different phases of face memory, studies combined with ERP may better isolate the neural responses of encoding and retrieval. Accordingly, these findings should not be overinterpreted, and more precise experimental conditions and large sample sizes would increase the strength of evidence. Third, the measurement of WCST could not precisely discriminate the diverse components of EF, and WCST only measures the cool EF. Consid- 
ering the significance of EF on the underlying mechanisms of neurocognitive changes in ASD, the relationship between EF and face memory should be thoroughly explored.

\section{Conclusions}

The present study confirmed that face memory in children with ASD was impaired in both the encoding and retrieving phases. Importantly, the study provides a new perspective and empirical evidence to show that co-occurring ADHD symptoms could modulate the face encoding deficits of ASD, which may be associated with EF. These findings, delineating the transdiagnostic profiles among participants with ASD, ADHD, and their comorbidity, propose that shared and distinct intervention approaches may be needed for children with each of the disorders, to improve social cognition. This study sheds light on the transdiagnostic neurocognitive basis of the conditions and emphasizes the importance of considering ADHD comorbidity in ASD when recommending treatment plans.

Supplementary Materials: The following are available online at https:/ /www.mdpi.com/article/ 10.3390/brainsci11070859/s1, Additional statement: The diagnosis procedure of ASD and ADHD. Table S1. Multiple regression analysis between EF and VSWM in different groups. Table S2. The correlation between face memory performance and symptoms of ASD and ADHD.

Author Contributions: Conceptualization, Z.W., Y.J., and Q.C. (Qi Chen); methodology, Z.W. and Q.C (Qi Chen).; software, Z.W.; validation, Z.W. and Y.J.; formal analysis, Q.C. (Qi Chen); investigation, Q.C. (Qi Chen), Q.C. (Qingxin Chen), and K.Z.; resources, Y.J and Z.W.; data curation, Q.C (Qi Chen) and Q.C. (Qingxin Chen); writing - original draft preparation, Q.C. (Qi Chen) and Z.W.; writingreview and editing, Q.C. (Qi Chen), Z.W., and B.W.; visualization, Q.C. (Qi Chen); supervision, Y.J.; project administration, Y.J.; funding acquisition, Y.J. and Z.W. All authors have read and agreed to the published version of the manuscript.

Funding: This work was supported by the National Natural Science Foundation of China (Grant No. 81171293) and Guangdong Basic and Applied Basic Research Foundation (Grant No. 2018A030310336, 2020A1515010942).

Institutional Review Board Statement: The study was conducted according to the guidelines of the Declaration of Helsinki, and approved by the medical ethics committee of School of Public Health, Sun Yat-Sen University (2019), No.90.

Informed Consent Statement: Informed consent was obtained from the guardians of all participants in the study.

Data Availability Statement: The datasets used and/or analyzed during the current study are available from the corresponding author on reasonable request.

Acknowledgments: The authors thank all of the children and parents who took part in the study and acknowledged all other participants involved in this research endeavor. Thank you for all co-authors' work the authors also thank the State Key Laboratory of Cognitive Neuroscience and Learning to provide the Chinese Facial Affective Pictures System for the stimuli of face encoding and retrieving task. Additionally, the authors are grateful for the help of Dan Chen to polish the language.

Conflicts of Interest: The authors declare that they have no conflict of interest.

\section{References}

1. Collin, L.; Bindra, J.; Raju, M.; Gillberg, C.; Minnis, H. Facial emotion recognition in child psychiatry: A systematic review. Res. Dev. Disabil. 2013, 34, 1505-1520. [CrossRef] [PubMed]

2. Neuhaus, E.; Kresse, A.; Faja, S.; Bernier, R.A.; Webb, S.J. Face processing among twins with and without autism: Social correlates and twin concordance. Soc. Cogn. Affect. Neurosci. 2016, 11, 44-54. [CrossRef]

3. Lewis, G.J.; Shakeshaft, N.G.; Plomin, R. Face Identity Recognition and the Social Difficulties Component of the Autism-Like Phenotype: Evidence for Phenotypic and Genetic Links. J. Autism Dev. Disord. 2018, 48, 2758-2765. [CrossRef]

4. Minio-Paluello, I.; Porciello, G.; Pascual-Leone, A.; Baron-Cohen, S. Face individual identity recognition: A potential endophenotype in autism. Mol. Autism 2020, 11, 81. [CrossRef]

5. Corbett, B.A.; Newsom, C.; Key, A.P.; Qualls, L.R.; Edmiston, E.K. Examining the relationship between face processing and social interaction behavior in children with and without autism spectrum disorder. J. Neurodev. Disord. 2014, 6, 35. [CrossRef] 
6. Webb, S.J.; Neuhaus, E.; Faja, S. Face perception and learning in autism spectrum disorders. Q. J. Exp. Psychol. 2017, 70, 970-986. [CrossRef]

7. Lord, C.; Bishop, S.; Anderson, D. Developmental trajectories as autism phenotypes. Am. J. Med. Genet. Part. C Semin. Med. Genet. 2015, 169, 198-208. [CrossRef]

8. Lord, C.; Elsabbagh, M.; Baird, G.; Veenstra-Vanderweele, J. Autism spectrum disorder. Lancet 2018, 392, 508-520. [CrossRef]

9. Lombardo, M.V.; Lai, M.C.; Baron-Cohen, S. Big data approaches to decomposing heterogeneity across the autism spectrum. Mol. Psychiatry 2019, 24, 1435-1450. [CrossRef] [PubMed]

10. Avni, E.; Ben-Itzchak, E.; Zachoro, D.A. The Presence of Comorbid ADHD and Anxiety Symptoms in Autism Spectrum Disorder: Clinical Presentation and Predictors. Front. Psychiatry 2018, 9, 717. [CrossRef] [PubMed]

11. Llanes, E.; Blacher, J.; Stavropoulos, K.; Eisenhower, A. Parent and Teacher Reports of Comorbid Anxiety and ADHD Symptoms in Children with ASD. J. Autism Dev. Disord. 2020, 50, 1520-1531. [CrossRef]

12. Kentrou, V.; De Veld, D.M.J.; Mataw, K.J.K.; Begeer, S. Delayed autism spectrum disorder recognition in children and adolescents previously diagnosed with attention-deficit/hyperactivity disorder. Autism 2019, 23, 1065-1072. [CrossRef]

13. Ameis, S.H. Heterogeneity Within and Between Autism Spectrum Disorder and Attention-Deficit/Hyperactivity Disorder Challenge or Opportunity? JAMA Psychiatry 2017, 74, 1093-1094. [CrossRef]

14. Carta, A.; Fuca, E.; Guerrera, S.; Napoli, E.; Valeri, G.; Vicari, S. Characterization of Clinical Manifestations in the Co-occurring Phenotype of Attention Deficit/Hyperactivity Disorder and Autism Spectrum Disorder. Front. Psychol. 2020, 11, 861. [CrossRef] [PubMed]

15. Young, S.; Hollingdale, J.; Absoue, M.; Bolton, P.; Branney, P.; Colley, W.; Craze, E.; Dave, M.; Deeley, Q.; Farrag, E.; et al. Guidance for identification and treatment of individuals with attention deficit/hyperactivity disorder and autism spectrum disorder based upon expert consensus. BMC Med. 2020, 18, 146. [CrossRef]

16. Locke, J.; Shih, W.; Kretzmann, M.; Kasari, C. Examining playground engagement between elementary school children with and without autism spectrum disorder. Autism 2016, 20, 653-662. [CrossRef]

17. Mikami, A.Y.; Miller, M.; Lerner, M.D. Social functioning in youth with attention-deficit/hyperactivity disorder and autism spectrum disorder: Transdiagnostic commonalities and differences. Clin. Psychol. Rev. 2019, 68, 54-70. [CrossRef]

18. Zaidman-Zait, A.; Mirenda, P.; Szatmari, P.; Duku, E.; Smith, I.M.; Zwaigenbaum, L.; Vaillancourt, T.; Kerns, C.; Volden, J.; Waddell, C.; et al. Profiles and Predictors of Academic and Social School Functioning among Children with Autism Spectrum Disorder. J. Clin. Child. Adolesc. Psychol. 2020, 1-13. [CrossRef]

19. Abikoff, H.; Hechtman, L.; Klein, R.G.; Gallagher, R.; Fleiss, K.; Etcovitch, J.; Cousins, L.; Greenfield, B.; Martin, D.; Pollalck, S. Social functioning in children with ADHD treated with long-term methylphenidate and multimodal psychosocial treatment. J. Am. Acad. Child. Adolesc. Psychiatry 2004, 43, 820-829. [CrossRef] [PubMed]

20. Ferretti, N.M.; King, S.L.; Hilton, D.C.; Rondon, A.T.; Jarrett, M.A. Social Functioning in Youth with Attention-Deficit/Hyperactivity Disorder and Sluggish Cognitive Tempo. Yale J. Biol. Med. 2019, 92, 29-35. [PubMed]

21. Berggren, S.; Engstrom, A.-C.; Bolte, S. Facial affect recognition in autism, ADHD and typical development. Cogn. Neuropsychiatry 2016, 21, 213-227. [CrossRef]

22. Suri, K.; Lewis, M.; Minar, N.; Willson, E.; Ace, J. Face Memory Deficits in Children and Adolescents with Autism Spectrum Disorder. J. Psychopathol. Behav. Assess. 2021, 43, 108-118. [CrossRef]

23. Field, T.M.; Woodson, R.; Greenberg, R.; Cohen, D. Discrimination and imitation of facial expression by neonates. Science 1982, 218, 179-181. [CrossRef]

24. Strauss, M.S.; Newell, L.C.; Best, C.A.; Hannigen, S.F.; Gastgeb, H.Z.; Giovannelli, J.L. The Development of Facial Gender Categorization in Individuals with and without Autism: The Impact of Typicality. J. Autism Dev. Disord. 2012, 42, $1847-1855$. [CrossRef] [PubMed]

25. Gaigg, S.B.; Bowler, D.M.; Ecker, C.; Calvo-Merino, B.; Murphy, D.G. Episodic Recollection Difficulties in ASD Result from Atypical Relational Encoding: Behavioral and Neural Evidence. Autism Res. 2015, 8, 317-327. [CrossRef] [PubMed]

26. Vanmarcke, S.; Wagemans, J. Priming Facial Gender and Emotional Valence: The Influence of Spatial Frequency on Face Perception in ASD. J. Autism Dev. Disord. 2017, 47, 927-946. [CrossRef] [PubMed]

27. Cooper, R.A.; Richter, F.R.; Bays, P.M.; Plaisted-Grant, K.C.; Baron-Cohen, S.; Simons, J.S. Reduced Hippocampal Functional Connectivity during Episodic Memory Retrieval in Autism. Cereb Cortex 2017, 27, 888-902. [CrossRef]

28. Lynn, A.C.; Padmanabhan, A.; Simmonds, D.; Foran, W.; Hallquist, M.N.; Luna, B.; O’Hearn, K. Functional connectivity differences in autism during face and car recognition: Underconnectivity and atypical age-related changes. Dev. Sci. 2018, 21, e12508. [CrossRef] [PubMed]

29. Krauel, K.; Duzel, E.; Hinrichs, H.; Rellum, T.; Santel, S.; Baving, L. Emotional memory in ADHD patients with and without comorbid ODD/CD. J. Neural Transm. 2009, 116, 117-120. [CrossRef]

30. Kim, S.; Liu, Z.X.; Glizer, D.; Tannock, R.; Woltering, S. Adult ADHD and working memory: Neural evidence of impaired encoding. Clin. Neurophysiol. 2014, 125, 1596-1603. [CrossRef] 
31. Tye, C.; Battaglia, M.; Bertoletti, E.; Ashwood, K.L.; Azadi, B.; Asherson, P.; Bolton, P.; McLoughlin, G. Altered neurophysiological responses to emotional faces discriminate children with ASD, ADHD and ASD+ADHD. Biol. Psychol. 2014, 103, 125-134. [CrossRef]

32. McVey, A.J.; Schiltz, H.K.; Haendel, A.D.; Dolan, B.K.; Willar, K.S.; Pleiss, S.S.; Karst, J.; Carlson, M.; Krueger, W.; Murphy, C.C.; et al. Social Difficulties in Youth With Autism With and Without Anxiety and ADHD Symptoms. Autism Res. 2018, 11, 1679-1689. [CrossRef]

33. Zachor, D.A.; Ben-Itzchak, E. From Toddlerhood to Adolescence: Which Characteristics among Toddlers with Autism Spectrum Disorder Predict Adolescent Attention Deficit/Hyperactivity Symptom Severity? A Long-Term Follow-Up Study. J. Autism Dev. Disord. 2019, 49, 3191-3202. [CrossRef]

34. Antshel, K.M.; Zhang-James, Y.; Wagner, K.E.; Ledesma, A.; Faraone, S.V. An update on the comorbidity of ADHD and ASD: A focus on clinical management. Expert Rev. Neurother. 2016, 16, 279-293. [CrossRef]

35. Van Hulst, B.M.; de Zeeuw, P.; Vlaskamp, C.; Rijks, Y.; Zandbelt, B.B.; Durston, S. Children with ADHD symptoms show deficits in reactive but not proactive inhibition, irrespective of their formal diagnosis. Psychol. Med. 2018, 48, 2515-2521. [CrossRef]

36. Hill, E.L. Evaluating the theory of executive dysfunction in autism. Dev. Rev. 2004, 24, 189-233. [CrossRef]

37. Brown, T.E. A New Understanding of ADHD in Children and Adults: Executive Function Impairments; Routledge: New York, NY, USA, 2013.

38. Demetriou, E.A.; Lampit, A.; Quintana, D.S.; Naismith, S.L.; Song, Y.J.C.; Pye, J.E.; Hickie, I.; Guastella, A.J. Autism spectrum disorders: A meta-analysis of executive function. Mol. Psychiatry 2018, 23, 1198-1204. [CrossRef] [PubMed]

39. Cleminshaw, C.L.; DuPaul, G.J.; Kipperman, K.L.; Evans, S.W.; Owens, J.S. Social Deficits in High School Students With Attention-Deficit/Hyperactivity Disorder and the Role of Emotion Dysregulation. Sch. Psychol. 2020, 35, 233-242. [CrossRef]

40. Fong, V.C.; Iarocci, G. The Role of Executive Functioning in Predicting Social Competence in Children with and without Autism Spectrum Disorder. Autism Res. 2020, 13, 1856-1866. [CrossRef]

41. Kercood, S.; Grskovic, J.A.; Banda, D.; Begeske, J. Working memory and autism: A review of literature. Res. Autism Spectr. Disord. 2014, 8, 1316-1332. [CrossRef]

42. De Vries, M.; Prins, P.J.; Schmand, B.A.; Geurts, H.M. Working memory and cognitive flexibility-training for children with an autism spectrum disorder: A randomized controlled trial. J. Child. Psychol. Psychiatry 2015, 56, 566-576. [CrossRef]

43. Zinke, K.; Fries, E.; Altgassen, M.; Kirschbaum, C.; Dettenborn, L.; Kliegel, M. Visuospatial Short-Term Memory Explains Deficits in Tower Task Planning in High-Functioning Children with Autism Spectrum Disorder. Child. Neuropsychol. 2010, 16, $229-241$. [CrossRef]

44. Van Ewijk, H.; Heslenfeld, D.J.; Luman, M.; Rommelse, N.N.; Hartman, C.A.; Hoekstra, P.; Franke, B.; Buitelaar, J.K.; Oosterlaan, J. Visuospatial working memory in ADHD patients, unaffected siblings, and healthy controls. J. Atten. Disord. 2014, 18, 369-378. [CrossRef]

45. Roselló, B.; Berenguer, C.; Navío, P.; Baixauli, I.; Miranda, A. Executive Functioning, Social Cognition, Pragmatics, and Social Interaction in Attention Deficit Hyperactivity Disorder and Autism Spectrum Disorder. Curr. Dev. Disord. Rep. 2017, 4, 72-77. [CrossRef]

46. Doyle, A.E.; Vuijk, P.J.; Doty, N.D.; McGrath, L.M.; Willoughby, B.L.; O’Donnell, E.H.; Wilson, H.K.; Colvin, M.K.; Toner, D.C.; Hudson, K.E.; et al. Cross-Disorder Cognitive Impairments in Youth Referred for Neuropsychiatric Evaluation. J. Int. Neuropsychol. Soc. 2018, 24, 91-103. [CrossRef]

47. Karalunas, S.L.; Hawkey, E.; Gustafsson, H.; Miller, M.; Langhorst, M.; Cordova, M.; Fair, D.; Nigg, J.T. Overlapping and Distinct Cognitive Impairments in Attention-Deficit/Hyperactivity and Autism Spectrum Disorder without Intellectual Disability. J. Abnorm. Child. Psychol. 2018, 46, 1705-1716. [CrossRef]

48. Vaidya, C.J.; You, X.Z.; Mostofsky, S.; Pereira, F.; Berl, M.M.; Kenworthy, L. Data-driven identification of subtypes of executive function across typical development, attention deficit hyperactivity disorder, and autism spectrum disorders. J. Child. Psychol. Psychiatry 2020, 61, 51-61. [CrossRef]

49. Wang, Z.; Jing, J.; Igarashi, K.; Fan, L.; Yang, S.; Li, Y.; Jin, Y. Executive function predicts the visuospatial working memory in autism spectrum disorder and attention-deficit/hyperactivity disorder. Autism Res. 2018, 11, 1148-1156. [CrossRef]

50. Neely, R.J.; Green, J.L.; Sciberras, E.; Hazell, P.; Anderson, V. Relationship Between Executive Functioning and Symptoms of Attention-Deficit/Hyperactivity Disorder and Autism Spectrum Disorder in 6-8 Year Old Children. J. Autism Dev. Disord. 2016, 46, 3270-3280. [CrossRef]

51. Salunkhe, G.; Weissbrodt, K.; Feige, B.; Saville, C.W.N.; Berger, A.; Dundon, N.M.; Bender, S.; Smyrnis, N.; Beauducel, A.; Biscaldi, M.; et al. Examining the Overlap Between ADHD and Autism Spectrum Disorder (ASD) Using Candidate Endophenotypes of ADHD. J. Atten. Disord. 2018, 25, 217-232. [CrossRef]

52. American Psychiatric Association. Diagnostic and Statistical Manual of Mental Disorders, 5th ed.; American Psychiatric Association: Washington, DC, USA, 2013.

53. Schopler, E.; Reichler, R.J.; DeVellis, R.F.; Daly, K. Toward objective classification of childhood autism: Childhood Autism Rating Scale (CARS). J. Autism Dev. Disord. 1980, 10, 91-103. [CrossRef]

54. Constantino, J.N.; Gruber, C.P. Social Responsiveness Scale, 2nd ed.; Western Psychological Services: Los Angeles, CA, USA, 2012.

55. Gau, S.S.; Shang, C.Y.; Liu, S.K.; Lin, C.H.; Swanson, J.M.; Liu, Y.C.; Tu, C.L. Psychometric properties of the Chinese version of the Swanson, Nolan, and Pelham, version IV scale-parent form. Int. J. Methods Psychiatr. Res. 2008, 17, 35-44. [CrossRef] 
56. Thimm, M.; Krug, A.; Markov, V.; Krach, S.; Jansen, A.; Zerres, K.; Eggermann, T.; Stöcker, T.; Shah, N.J.; Nöthen, M.M.; et al. The impact of dystrobrevin-binding protein 1 (DTNBP1) on neural correlates of episodic memory encoding and retrieval. Hum. Brain Mapp. 2010, 31, 203-209. [CrossRef]

57. Krug, A.; Krach, S.; Jansen, A.; Nieratschker, V.; Witt, S.H.; Shah, N.J.; Nöthen, M.M.; Rietschel, M.; Kircher, T. The effect of neurogranin on neural correlates of episodic memory encoding and retrieval. Schizophr Bull. 2013, 39, 141-150. [CrossRef] [PubMed]

58. Dietsche, B.; Backes, H.; Stratmann, M.; Konrad, C.; Kircher, T.; Krug, A. Altered Neural Function During Episodic Memory Encoding and Retrieval in Major Depression. Hum. Brain Mapp. 2014, 35, 4293-4302. [CrossRef]

59. Landry, O.; Al-Taie, S. A Meta-analysis of the Wisconsin Card Sort Task in Autism. J. Autism Dev. Disord. 2016, 46, 1220-1235. [CrossRef]

60. Xu, C.J.; Zhang, L.; Pan, N.; Lin, Q.X.; Ye, J.; Jing, J.; Jin, Y. Event-related potential of working memory on emotional faces in children with autism spectrum disorder. Zhongguo Dang Dai Er Ke Za Zhi 2017, 19, 280-285. (In Chinese)

61. Dwyer, P.; Xu, B.Y.; Tanaka, J.W. Investigating the perception of face identity in adults on the autism spectrum using behavioural and electrophysiological measures. Vis. Res. 2019, 157, 132-141. [CrossRef] [PubMed]

62. O'Hearn, K.; Larsen, B.; Fedor, J.; Luna, B.; Lynn, A. Representational similarity analysis reveals atypical age-related changes in brain regions supporting face and car recognition in autism. Neuroimage 2020, 209, 116322. [CrossRef]

63. Koshino, H.; Kana, R.K.; Keller, T.A.; Cherkassky, V.L.; Minshew, N.J.; Just, M.A. FMRI investigation of working memory for faces in autism: Visual coding and underconnectivity with frontal areas. Cereb. Cortex 2008, 18, 289-300. [CrossRef]

64. Seng, G.-J.; Tseng, W.-L.; Chiu, Y.-N.; Tsai, W.-C.; Wu, Y.-Y.; Gau, S.S.-F. Executive functions in youths with autism spectrum disorder and their unaffected siblings. Psychol. Med. 2020, 1-10. [CrossRef]

65. Lee, S.E.; Kibby, M.Y.; Cohen, M.J.; Stanford, L.; Park, Y.; Strickland, S. Differences in memory functioning between children with attention-deficit/hyperactivity disorder and/or focal epilepsy. Child. Neuropsychol. 2016, 22, 979-1000. [CrossRef]

66. Romani, M.; Vigliante, M.; Faedda, N.; Rossetti, S.; Pezzuti, L.; Guidetti, V.; Cardona, F. Face memory and face recognition in children and adolescents with attention deficit hyperactivity disorder: A systematic review. Neurosci. Biobehav. Rev. 2018, 89, 1-12. [CrossRef] [PubMed]

67. Ioannou, C.; Seernani, D.; Stefanou, M.E.; Riedel, A.; Tebartz van Elst, L.; Smyrnis, N.; Fleischhaker, C.; Biscaldi-Schaefer, M.; Boccignone, G.; Klein, C. Comorbidity Matters: Social Visual Attention in a Comparative Study of Autism Spectrum Disorder, Attention-Deficit/Hyperactivity Disorder and Their Comorbidity. Front. Psychiatry 2020, 11, 545567. [CrossRef] [PubMed]

68. Fujioka, T.; Tsuchiya, K.J.; Saito, M.; Hirano, Y.; Matsuo, M.; Kikuchi, M.; Maegaki, Y.; Choi, D.; Kato, S.; Yoshida, T.; et al. Developmental changes in attention to social information from childhood to adolescence in autism spectrum disorders: A comparative study. Mol. Autism 2020, 11, 24. [CrossRef]

69. Kim, S.Y.; Song, D.-Y.; Kim, Y.A.; Bong, G.; Kim, J.-M.; Kim, J.H.; Yoo, H.J. How Do Children with Autism Spectrum Disorder Encode and Reproduce Visuospatial Stimuli?: Investigation into Visuospatial Processing Abilities and Styles. Psychiatry Investig. 2020, 17, 1105-1107. [CrossRef]

70. Li, S.Z.; Hu, J.S.; Chang, R.S.; Li, Q.; Wan, P.; Liu, S.Q. Eye Movements of Spatial Working Memory Encoding in Children with and without Autism: Chunking Processing and Reference Preference. Autism Res. 2021, 14, 897-910. [CrossRef]

71. Desaunay, P.; Briant, A.R.; Bowler, D.M.; Ring, M.; Gerardin, P.; Baleyte, J.M.; Guénolé, F.; Eustache, F.; Parienti, J.-J.; GuilleryGirard, B. Memory in Autism Spectrum Disorder: A Meta-Analysis of Experimental Studies. Psychol. Bull. 2020, 146, 377-410. [CrossRef]

72. Tye, C.; Asherson, P.; Ashwood, K.L.; Azadi, B.; Bolton, P.; McLoughlin, G. Attention and inhibition in children with ASD, ADHD and co-morbid ASD plus ADHD: An event-related potential study. Psychol. Med. 2014, 44, 1101-1116. [CrossRef]

73. Cowan, N. Evolving conceptions of memory storage, selective attention, and their mutual constraints within the human information-processing system. Psychol. Bull. 1988, 104, 163-191. [CrossRef] [PubMed]

74. Engle, R.W. Working memory capacity as executive attention. Curr. Dir. Psychol. Sci. 2002, 11, 19-23. [CrossRef]

75. Sinzig, J.; Morsch, D.; Lehmkuhl, G. Do hyperactivity, impulsivity and inattention have an impact on the ability of facial affect recognition in children with autism and ADHD? Eur. Child. Adoles. Psy. 2008, 17, 63-72. [CrossRef]

76. Livingston, L.A.; Happe, F. Conceptualising compensation in neurodevelopmental disorders: Reflections from autism spectrum disorder. Neurosci. Biobehav. Rev. 2017, 80, 729-742. [CrossRef]

77. Livingston, L.A.; Colvert, E.; Bolton, P.; Happe, F.; Social Relationships Study Team. Good social skills despite poor theory of mind: Exploring compensation in autism spectrum disorder. J. Child. Psychol. Psychiatry 2019, 60, 102-110. [CrossRef]

78. Livingston, L.A.; Shah, P.; Happe, F. Compensatory strategies below the behavioural surface in autism: A qualitative study. Lancet Psychiatry 2019, 6, 766-777. [CrossRef]

79. Herrington, J.D.; Riley, M.E.; Grupe, D.W.; Schultz, R.T. Successful face recognition is associated with increased prefrontal cortex activation in autism spectrum disorder. J. Autism Dev. Disord. 2015, 45, 902-910. [CrossRef]

80. Hogeveen, J.; Krug, M.K.; Geddert, R.M.; Ragland, J.D.; Solomon, M. Compensatory Hippocampal Recruitment Supports Preserved Episodic Memory in Autism Spectrum Disorder. Biol. Psychiatry Cogn. Neurosci. Neuroimaging 2020, 5, 97-109. [CrossRef]

81. Lukito, S.; Jones, C.R.G.; Pickles, A.; Baird, G.; Happe, F.; Charman, T.; Simonoff, E. Specificity of executive function and theory of mind performance in relation to attention-deficit/hyperactivity symptoms in autism spectrum disorders. Mol. Autism 2017, 8, 60. [CrossRef] 
82. Holland, L.; Low, J. Do children with autism use inner speech and visuospatial resources for the service of executive control? Evidence from suppression in dual tasks. Br. J. Dev. Psychol. 2010, 28, 369-391. [CrossRef]

83. Macoun, S.J.; Schneider, I.; Bedir, B.; Sheehan, J.; Sung, A. Pilot Study of an Attention and Executive Function Cognitive Intervention in Children with Autism Spectrum Disorders. J. Autism Dev. Disord. 2020. [CrossRef] 